\title{
English as a Global Lingua Franca: Intercultural Communication in Zimbabwean Business Set up
}

\author{
Mrs Precious Dube \\ Midlands State University, Private Bag 9055, Gweru
}

\begin{abstract}
With globalisation of the world, more and more people from different countries have begun to develop business in Zimbabwe. Zimbabwe's former" Look East" policy, which aimed at expanding bilateral and trade relations and offer priority to investors from China, Malaysia, Singapore, Vietnam, Japan, South Korea, India, and Russia among other nations, has also expanded this global village. However, because of different cultural backgrounds, language, markets and social mores, these traders face many challenges and in trying to adjust themselves to new settings. This is mainly because; Zimbabwe is a multicultural and multilingual country with so many languages being spoken. English is the official language and Shona and Ndebele are national languages and therefore English has become the global lingua franca. Although some researchers hold that, English as a lingua franca is a neutral and culture-free tool (House 2002;2003). Others assert that, it carries the culture and language of its speakers ( Pölzl 2005 and Klimpfinger, 2005). Recent linguistic discussions by ELF experts treat the interlocutors' cultural and linguistic background as a factor influencing language performance. Generally speaking, ELF interactions concentrate on function rather than form. In other words, communicative efficiency (i.e. getting the message across) is more important than correctness (Cogo 2008). As a result, ELF interactions are very often tolerant with each other. Speakers accommodate each other's cultural backgrounds. They also use various verbal and nonverbal communication strategies in order to be able to communicate with each other. English as a language is therefore used as "a common means of communication for these speakers of different first languages"(Vienna Oxford). In English Lingua Franca (ELF) interactions, the importance lies on communication strategies other than nativeness, which can lead to communicative situations where those English native speakers who are not familiar with ELF and/or intercultural communication are at a disadvantage because they do not know how to use English appropriately in these situations (Hülmbauer 2008).Using the inter-language theory, this paper would like to look at the changes taking place in the world system of languages because of the transformation of the English language into a Global Language. It also seeks to analyse communication strategies which are used by international business traders and the indigenous customers in Zimbabwe in a bid to communicate during their business transactions.

Key Terms: Global Lingua franca, Intercultural communication, Communication strategies, Inter-language, Culture, Nonverbal communication, International business traders, Indigenous customers National language Official language.
\end{abstract}

DOI: $10.7176 / \mathrm{RHSS} / 9-24-05$

Publication date: December $31^{\text {st }} 2019$

\subsection{BACKGROUND OF THE STUDY}

The researcher decided to carry out this research because she recognised that, with globalisation of the world and the famous call by the Zimbabwean President that 'Zimbabwe is open for business', people from different countries have begun to develop business in Zimbabwe for example, Chinese, Nigerians, Indians, Zambians, Japanese Mozambiquians and also South Africans among other traders. Zimbabwe's "Look East" policy, which aimed to expand bilateral and trade relations and offer priority to investors from China, Malaysia, Singapore, Vietnam, Japan, South Korea, India, and Russia, has also expanded this global village. However, because of different languages, cultural backgrounds, markets and social mores, these traders face many challenges in trying to adjust themselves to new settings. This is mainly because; Zimbabwe is a multicultural and, multilingual country with so many languages being spoken. English is the official language for business, academic and occupational purposes while Shona and Ndebele are the national languages.

According to Chimhundu (1995) Shona is the most largely spoken language by at least $75 \%$ of the total population in Zimbabwe and is followed by Ndebele which is spoken by up to $16.5 \%$. However most of the International business are not proficient in these indigenous languages, neither are they conversant in the English Language, which is the official language in the country and also the global lingua franca, meaning that it is the language which is used for communication around the global village.

In countries like India and China, English is not the official language of business and academics; but when business men from these countries come to Zimbabwe, they would need to communicate with local customers in order to market and sell their products so they try to adopt English (for business purposes) and at times together with indigenous languages as their language(s) for communication purposes. However, since they are not very competent in the English language and are not well versed with Zimbabwean indigenous languages and culture, they therefore devise some communication strategies which would help them to be able to communicate in order 
to facilitate trade between them and the indigenous people. Some of these strategies may be successful and some may not. This study is an exploration the various communication strategies used by these traders who are not very competent in the country s' languages in interacting with their customers.

\subsection{STATEMENT OF THE PROBLEM}

Past research on intercultural communication has looked at so many other issues but, did not deal with the importance of English as a global lingua Franca in intercultural communication in a Zimbabwean, business context, an area which is very crucial in strategic communication. This study will therefore analyse the importance of English as a form of communication especially in business context and the other strategies which are used by Chinese business traders in Zimbabwe and their indigenous customers, in their endeavour to communicate when conducting business together, an area which not many scholars have yet looked in to.

\subsection{AIMS}

The aim of this research is to analyse the importance of English in intercultural communication and other strategies which are used by international business traders when communicating with indigenous Zimbabwean customers.

\subsection{OBJECTIVES}

- Assess the importance of English as a global lingua franca in intercultural communication

- Analyse how language, cultural differences and other key barriers affect intercultural communication.

- Identify and analyse other verbal and non-verbal intercultural communication strategies employed by international business traders when conducting their day today business.

\subsection{SIGNIFICANCE OF THE STUDY}

Since the world is shrinking in size due to globalisation, this study aims to encourage every individual to be able to communicate in English which is the primary language of the global village. This helps communication to be very easy and avoid misinterpretation and misperception.

This research however intends to benefit international business traders in Zimbabwe as they will learn how to communicate with customers in a new environment so as to avoid misinterpretation and misperception. It can also help indigenous customers to understand the language used by foreign business traders when they communicate to avoid misunderstanding.

The research may also help linguists interested in language and how it is used, as both international business traders and native consumers will have an insight into the language used to communicate. This work may be of great importance to the academic field, as it may support future researchers who may find it useful in the creation of literature for the purposes of review.

It exposes policymakers and psycholinguists on the role of linguistic policy in intercultural communication and can also convince linguists to work towards linguistic liberalism. As input for language policy and planning in Zimbabwe aimed at linguistic liberalism, the results of this research are very important. It is also expected that during language debate forums, I will be an eye opener.

This research will also amplify one's understanding of intercultural communication and generate new knowledge in the area of strategic communication thereby filling the gap that exist in this area.

\subsection{DELIMITATIONS OF THE STUDY}

Business traders who were used in this study are Chinese traders because they seem to be the most popular traders in the country selling attractive goods at affordable prices such that, many people flock to their shops. A sample was taken from Chinese traders and indigenous customers mainly in Harare where most of these traders are concentrated.

\subsection{LITERATURE REVIEW \\ 2.1 Globalization}

David (2002) says that, globalization is the process of harmonizing different cultures and beliefs. Orunmoluyi (2002) on the other hand defines it as, a process of creating a global market in which increasingly all nations are forced to participate. Intercultural communication started due to globalisation where many people from around the globe moved from one country to another because of business and trade. This means that, there was need for communication and English was made the language of globalisation. Research has shown that, awareness of globalization is on the increase that no one wants to be left out. However for people to fit into the global village there is need for communication and that communication is possible only through the use of the English language which is the language of the global village.

Globalization has actually made English language, a predator language, Crystal (2003:1) has observed this when he says, "English is an apt symbol for the themes globalization, diversification, progress and identity. For 
one to be able to fit in to the global village, one has to be able to communicative in English, the global language that is spoken all over the world. This means that, Chinese business traders and indigenous Zimbabwean customers both have to be able to speak and understand the English language so that they are both able to communicate effectively with each other. Globalization has a lot to do with peoples aspirations. Success is almost measured against individual's ability to participate in the global village, so everyone has to be part of globalization.

\subsection{English as a lingua franca,}

In using this term Jenkins (2009) was referring to a specific communication context; that is, English being used as a lingua franca, the common language of choice, among speakers who come from different linguacultural backgrounds. According to Kirkpatrick (2013) the origin of the term 'lingua franca' stems from when Germanic Franks moved into Gaulin the 5th century and adopted the local language, which became known as the language of the Franks, or lingua franca. The term then came to mean an unofficial language of wider communication and was first used in the Levant during the medieval period, when the 'Franks' went on crusades. A derivation from 'frank' gives Arabic its word for foreigner (Ostler 2005). If, on the other hand, the term is to be treated as an English word, the 'proper' plural should be linguas franca. A lingua franca can thus be defined as a common language between people who do not have a mother tongue (Kirkpatrick 2013). a Firth (1996)gives a more precise definition saying, a lingua franca is a 'contact language' between persons who share neither common native tongue nora common (national) culture, and for whom English is the chosen foreign language of communication.(Firth 1996: 240)

This suggests that a lingua franca offers no necessary linguistic advantages to any speaker.With English, of course, this is not the case when English is used as a lingua franca betweenL1 speakers of English and others. This is a reason why certain scholars view English as alingua franca with concern, with one referring to it as a 'Lingua Frankensteinia' (Phillipson2008).

\subsection{Intercultural communication}

The term intercultural communication which is also known as cross cultural communication was first conceptualized by Edward T Hall in the early 1950s, who later on popularized it in his book, The Silent Language, in 1959. It is simply defined as, interpersonal communication between members of different cultures. According to Chiwome and Gambaya (1996), cross cultural communication looks at how people from different cultural backgrounds endeavour to communicate. This is one of the most complex areas of human interaction because there are so many barriers which impede effective communication between people from different cultural groups. Gao (2005) mentions that, the differences are reflected not only in different pronunciation, grammatical structures, and choice of words, but also in cultural norms and modes of communication. Intercultural business communication, which this study is concerned about, is relatively a new term in the business world and Cleary (2003) defined it as, 'communication within and between businesses that involve people from more than one culture'. This study is looking at communication between Chinese business traders and indigenous customers in Zimbabwe who communicate with each other while conducting business together.

\subsection{Practical considerations to better intercultural communication}

Duggan (2005) has noted that, today's workplace is rapidly becoming vast, as the business environment expands to include various geographic locations and span numerous cultures. What can be difficult however is understanding how to communicate effectively with individuals who speak another language who rely on different means to reach a common goal. Global business professionals however require skills in intercultural communication, because they typically exchange information with people from all over the world. Without knowledge of other cultures people tend to make embarrassing mistakes when concluding intercultural business. These errors confuse and offend business partners and make effective communication difficult.

\subsection{Importance of intercultural communication}

Because of Globalisation, the world in shrinking in size, making intercultural communication inevitable. Communicating with other cultures characterizes today's business, classroom and community; hence the art of knowing how to communicate with other cultures should be a work place skill that should be emphasized (Cleary 2003). Cleary (ibid) also observed that, at the economic level, Zimbabwe trades with nations as diverse as China with a unique culture and systems, different from our own. Zimbabweans therefore need to be informed about the cultural expectations of their trading partners, in order to facilitate communication with them.

Gitimu (2003) postulates that the business sector is probably the most affected, with the issues of intercultural communication. Today with the emergence of multinational companies it is unlikely to do business without communicating cross culturally. Targowski and Metwalli (2003) cited in Gitimu (2003) viewed this millennium as era that, global organizations will increasingly focus on the critical value of cross cultural communication process efficiency and competence and cost of doing business. In order to successfully communicate cross 
culturally, knowledge and understanding of cultural factors such as values, attitudes, beliefs, behaviour should be acquired. Effective cross cultural communication in global economy provides pragmatic tools about how to define a communication strategy, train representatives and conduct business talks in order to achieve success.

\subsection{Communication strategies}

The term communication strategy was introduced by Selinker in 1972 and the first systematic analysis of communication strategies was made by Varandi in 1973. Bialystock (1993) quotes Corder (1977) who says, communication strategies are, 'a technique employed by a speaker to express his meaning when faced with some difficulty'. She also gives Tarone (1980)'s definition which says that, they are a mutual attempt of two interlocutors to agree on a meaning in situations where requisite meaning structures are not shared.

There are two taxonomies of communication strategies. The first is given by Dornyei (1995) cited in Brown (2000:125) and the Second one is from Tarone (1977) cited in Bialystok (1990:39). Two branches given by Dornyei (ibid) reveal two opposite directions in communication. One is avoiding and the other is compensating. Avoidance strategies can be further broken down into several subtypes such as phonological avoidance, syntactical or lexical avoidance and topic avoidance and topic avoidance (Brown 2000:125). These strategies may be effective but not beneficial to second languages learners. Compensatory strategies on the other hand, involve, compensation for missing knowledge (ibid, 129).

Dorneyi outlines eleven types of compensatory strategies in a very comprehensive way. These include circumlocution, word coinage, prefabricated patterns, appetizing for help and stalling, or time -gaining strategies (Dorneyi (1995) cited in Brown 2000). Some of them happen in a high frequency, while others may seldom occur, for example, foreignizing, which refers to "using a first language word by adjusting it to second language phonology and or morphology (ibid)". Chinese speakers will find it hard to use a Chinese character to neither substitute the pronunciation of an English word nor just simply add an English suffix to it, for Chinese and English are very different types of language.

\subsection{Barriers to intercultural communication}

Communicating across cultures carries myriad challenges and scholars have studied the process for decades. Intercultural communication can present complex obstacles that cover the full communication spectrum. There are some important oral and non-verbal factors can make a significant difference when communicating with individuals from another culture, these include, personal Space, time, language and cultural norms among other barriers (Brown, 2000).

Samovar and Porter (1991) postulate that, people who do not share a language or who feel that, they have imperfect command of another person's language may have some difficulties communicating. He noted that, many misunderstandings may occur when people do not speak a common language, but this does not mean that, people who speak the same language always understand each other. Even speakers of the same language do not have exactly the same understanding of the meanings of words. He gives the example of Americans and Australians who use quite different vocabulary for some things and have different slang, although they all have English as their first language.

Jandt (2001) has noted that, language can also be a barrier to intercultural communication because of problems of vocabulary equivalence, idiomatic equivalence, experiential equivalence, and conceptual equivalence. He says that, vocabulary equivalence occurs when there are no words in one language that correspond precisely with the meaning of words in another. This occurs particularly with specific or very descriptive words.

Non-verbal communication (NVC) is another factor which can have a negative impact on intercultural communication. This refers to communication without words. Messages are sent through gestures, proximity, eye contact, expectations regarding time among other nonverbal forms of communication. Anecdotal evidence suggests that, each culture has a different way of interpreting these, which results in barriers to intercultural communication because these forms of communication can easily be misinterpreted (Jandt 2001).

Intercultural communication deals with communication between people from different cultural groups which is one of the most complex areas of human interaction. Walter Goodenough an anthropologist in Kaschuka and Antonissen, (1995) defines culture as, the particular knowledge and beliefs that members of a community have, which enable them to operate in a manner acceptable to the group and in any role that, the group finds acceptable. This means that, people of a particular culture have shared values, beliefs, rules of behaviour and a shared symbolic code such as language which binds them together and gives them a sense of belonging. This however shows that, it is crucial for one to have an insight or some knowledge of another person's culture in order to be able to communicate with them effectively in intercultural communication. LeBaron (2003) states that the challenge we are facing is that distinctive cultural differences may cause misunderstanding or even conflict, even though we have a good intention during communication. If we know about differences between cultures, we will develop awareness that culture influences communication in a way and improve our communicative ability to avoid conflicts when encountering cultural differences (LeBaron, 2003). 


\subsection{THEORETICAL FRAMEWORK}

This study will use the inter-language theory as its theoretical framework. The term 'Interlanguage' was coined by the American linguist Larry Selinker (1969:1972) to refer to an emerging linguistic system that has been developed by a learner of a second language who has not become fully proficient but yet is approximating the target language (TL), "preserving some features of the first language rules in speaking or writing the second language and creating innovations". This implies that, the language comprise of certain grammatical implications some of which are true to the TL and some which might not be. This is the kind of language produced by foreign traders in Zimbabwe. This is mainly due to factors like interference of the first language rules to the target language, overgeneralization and simplification. Some linguists would like to call this type of language, "language, learner, language"

The concept of interlanguage involves the following premises about SLA as Ellis (1994) says.

- The leaner constructs a system of abstract linguistic rules which underlies comprehension and production of the L2. This system of rules is viewed as a mental grammar and is referred to as an Interlanguage.

- The learner's grammar is permeable, meaning that, it is open to influence from the outside through input and also from inside as seen through omission, overgeneralization and transfer.

- The grammar of the learner is also transitional, that is, it changes from one time to another by adding rules deleting rules and also restructuring the whole process and this result in an interlaguage continuum.

- Some scholars claim that, the systems learners construct contain variable rules, meaning that, they are likely to have competing rules at any one stage of development although the aspect of variability is a disputed one.

- Learners employ various learning strategies to develop their interlnguages and the different kinds of errors learners produce reflect different learning strategies.

- The learner's grammar is also likely to fossilise. (This is the state of affairs that exists when the learner ceases to elaborate the interlanguage in some respect, no matter how long there is exposure, new data and new teaching).

Selinker suggests that only about $5 \%$ of learners go on to develop the same mental grammar as native speakers. The prevalence of backsliding (production of errors representing an early stage of development) is typical of fossilized learners.

Corder (1971) suggests that, there is structure in learner language, and that certain inferences can be made about the learning process by describing successive states of the learner language, noting the changes and correlating this with the input. Interlanguage is riddled with errors which are caused by various factors as the learner (acquirer) processes and uses the target language, which means, some of the utterances produced by learners are not well formed according to the rules of the target grammar. This indicates that, learners do not simply memorise the target language rules and reproduce them in their own language utterances. They instead construct their own rules on the basis of input data and in some utterances at least these rules differ from those of the target language. Corder (1971) however argues that, the appearance of errors in a learner's production is evidence that, the learner is organising the knowledge available to him or her at a particular point in time. Errors, he states, are the most important source of information, accounting for the fact that learners have a 'built in syllabus' and that a process of hypothesis formulation.

Learners differ in their acquisition developments as they try to achieve native like use of the target language and this brings in variability in their interlanguage. Variability is a result of internal (psychological) conditions which are individualistic in nature, for example, motivation and aptitude; and also social factors such as input and interaction among other factors. This variability can either be systematic or non-systematic but this study shall concentrate on interlanguage in general and not variability in interlanguage.

Selinker (1972) further postulates that, interlanguage is a separate linguistic system constructed by the learner as the result of five central cognitive processes namely, Language transfer from mother tongue, Transfer of training resulting from special features of instruction, Second language learning strategies, Second language communication strategies and also overgeneralisation of the rules of the target language. Ellis (1985) also proposes that, interlanguage develops simultaneously in three phases which are; Innovation- the acquisition of new terms, Elaboration- the use of more complex language as the use of forms in different contexts is developed, and also Revision- the adjustments of language that are made as a result of innovation and elaboration.

Nemser (1971) says, the interlanguage theory assumes that, at any given time, the approximative system is different from L1 and L2, meaning that it is a distinct language on its own. It also assumes that, the approximative systems form an evolving series and in a given contact situation, the approximative systems of learners at the same stage of proficiency roughly coincide. The Interlanguage theory, according to Frith (1977), also assumes that, an active and independent learning mind makes its own generalizations upon grappling with a new language and further argues that the errors that a learner makes in the rules of the target language are often in fact "correct" by 
the rules of an "interlanguage" invented by the learner as a provisional and sufficiently workable substitute. To insist on penalising all such "errors" has the effect of breaking down the learner's capacity to organize his or her progress in this way. Language learning is seen as a process which involves the construction of an IL, a 'transitional competence' reflecting the dynamic nature of the learner's developing system.

Duran (2005:1) postulates that "Interlanguage may be viewed as an adaptive strategy in which the speaker tries to speak the interlocutor's L1 although he has little proficiency in it." This strategy uses simplification, reduction, overgeneralization, transfer, formulaic language, omissions, substitutions, and restructurings (Selinker, 1972). Ellis (1985) concurs adding that this is because of the interpretation of interlanguage as the language a learner has constructed at a specific point in time in the developmental continuum from L1 to TL.

For Klein (1986), interlanguages or learner-language varieties should be viewed not only as systematic as well as variable but also as creative with rules unique to itself and not just a borrowed form of the other languages. He says that however, imperfect from a normative point of view, these means represent the learner's current repertoire and, as such, a learner variety of the target language. He concludes that the process of language acquisition can be construed as a series of transitions from one variety to the next. Corder (1981) defines the structural properties of interlanguage as: (a) a simple morphological system, (b) a more or less fixed word order, (c) a simple personal pronoun system, (d) a small number of grammatical function words, (e) little or no use of the copula, and (f) the absence of an article system. He describes the interlanguage notion as "transitional language" and presents a model which is inaccurate in various respects but is always more or less complete. For Corder (1974), it is a working model, a grammar, a system which can be used quite effectively for communicative purposes. It presupposes that the language learner at all points of his learning career "has a language."

Ellis (1985) explains interlanguage as the theoretical construct which underlies the attempts of SLA researchers to identify the stages of development through which L2 learners pass on their way to L2 or near L2 proficiency. He says learners do not progress from zero knowledge of a target rule to perfect knowledge of the rule but, rather, they progress through a series of interim or developmental stages on their way to target language competence. Interlanguage is also described as permeable, dynamic, changing, and yet systematic (Corder, 1975; Selinker, 1972 and Ellis 1985). Ellis concurs that, it is permeable in the sense that, rules that constitute the learner's knowledge at any one stage are not fixed but are open to amendment. It is dynamic in that, the second language learner's interlanguage is constantly changing. The learner does not jump from one stage to the next, but rather slowly revises the interim systems to accommodate new hypothesis about the target language systems. It is also systematic in that, despite the variability in interlanguage, it is possible to detect the rule based nature of the learner's use of the second language. The learner does not select haphazardly from his store of interlanguage rules, but in predictable ways.

The key pillars of the Interlanguage Theory can therefore be summarised as follows:

- The Interlanguage hypothesis sees errors as evidence of L2 learners' strategies of learning, rather than as signs of interference or as the persistence of "bad habits" which should be eradicated as quickly as possible through practice, drill and over-learning of the correct forms.

- The making of errors helps the learner to test hypotheses about the TL system.

- A study of errors should help to uncover the learner's built-in syllabus and his learning strategies.

The interlanguage theory is quite suitable for this study because, it is a theory which explains how second languages are learned. Second language learners produce a kind of language that is between their first language and their target language using so many communication strategies. The utterances produced are not identical to those produced by native speakers of the TL, nor are they exact "translations" from the native language of the learners. Rather, a new, separate system develops. This is what Chinese business traders and indigenous customers do when communicating during their business transactions.

\subsection{RESEARCH DESIGN}

This study has used a descriptive survey as the appropriate research design. Chiromo $(2006,29)$ says that, 'a survey is a method of research which describes what we see. A descriptive survey, therefore, means describing what one is seeing over and beyond the horizon. A survey research method involves the use of questionnaires and observation to gather data about people, their thoughts and behaviours.

\subsection{Qualitative approach}

The current study used a qualitative approach which involves direct experience during field work in order to be able to understand and interpret the setting as well as the individuals (Creswell 2003). According to Almeida (2017), the objective of the qualitative methodology is to produce in-depth and illustrative information in order to understand the various dimensions of the problem under analysis. Almeida also says that, qualitative research is therefore concerned with aspects of reality that cannot be quantified, focusing on the understanding and explanation of the dynamics of social relations. 


\subsection{Research Instruments}

This study uses observation and conversation analysis as its research instruments.

\subsubsection{Observation}

Participant observation used in this study made it possible for the researcher to collect information in a natural setting, making the collected data very authentic. The researcher observed the co-operationof international business traders and indigenous customers. She was able to develop non-verbal and verbal communication strategies that were used by both parties in an effort to make their communication a success. This allowed the researcher to gather authentic information without being prejudiced by the informants. This helped the information gathered to be real and true.

\subsubsection{Conversation analysis}

In this study, conversations were recorded using an audio voice recorder and then analyzed to find the verbal strategies and non-verbal communication strategies used by international business traders as well as indigenous customers to make their communication effective. The researcher then transcribed the conversations in writing.

\subsection{RESEARCH FINDINGS}

In this analysis, a sample of 30 respondents from Harare City was used, 10 of whom were Chinese business traders and 20 were Zimbabwean indigenous clients. To carry out this research, the researcher used the survey method. To capture data from the sampled respondents, the researcher used semi-structured face-to-face interviews, observation and conversation analysis. The valid study. An analysis of the validity and reliability of the chosen instruments was carried out and the reasons why they were chosen were strongly justified.

\subsection{Findings.}

From the findings, respondents said that, it was very important to know the English language since it is a global language which makes communication between people of different cultures and languages be able to communicate effectively. They appreciated the importance of knowing English as a global lingua franca. It was observed that, $60 \%$ of the Indigenous customers use verbal communication strategies when speaking to Chinese traders. This is probably because; most Zimbabweans can communicate in English although at times with difficulty because it is the official language and it also belongs to the same group of languages with Bantu languages like Shona and Ndebele. However $40 \%$ rely mostly on non- verbal communication strategies either because they lack appropriate vocabulary in the English language or it will be to enhance verbal language.

Findings also revealed that, culture differences are also a major barrier to effective intercultural communication. People from different cultures behave differently and also have different ways of communicating so it is important to be aware of one's culture in order to communicate effectively. Since the Chinese accent and Zimbabwean accent are somewhat different, some Chinese traders and indigenous customers prefer to write down words that sound different when spoken by a person from a different cultural background so that they can clearly understand what the other person is trying to say. Research has shown that, to both Chinese business traders and the indigenous Zimbabwean customers, language barriers exist at the root of intercultural communication. The researcher -observed that, it is difficult for people who do not share the same language to communicate and effectively understand each other. Since English is a second language to both Chinese and Zimbabwean people, at times both these groups lack appropriate vocabulary which limits them when they communicate with each other. This would usually make them resort to strategies previously discussed in this chapter, such as word coinage, approximation, paraphrasing or circumlocution among other verbal strategies. This is because they do not have sufficient vocabulary to express themselves in English.

It was also observed that, another language barrier pertains to the accent with which some of the English words are pronounced. The way Chinese people pronounce some of English words makes them difficult to understand especially to someone who is not very familiar with the accent because, Zimbabwean accent and Chinese accent are at times different.

It was also found out that both groups prefer to use simple language which is explicit and direct. This helps them to be able to put their ideas across in an unambiguous manner in order to avoid miscommunication and misinterpretation. The fact that, Zimbabweans come from a high context culture, has little influence on the way they use English. They prefer to use a direct communication style which is a typical characteristic of low context cultures. However, in terms of the Chinese group, which is supposedly a low-context culture, their responses to the type of language they use when they communicate with indigenous customers confirm the high and low context communication. One, can therefore, conclude that, indigenous Zimbabweans have been successfully acculturated to the Western environment which uses low context communication.

Just $20 \%$ of the indigenous customers repeat themselves before they are understood. However $80 \%$ of the Chinese traders repeat themselves before they are understood. This is probably because of their accent. The way Chinese people pronounce some English words is a bit difficult to understand especially for someone who is not familiar with their accent. They for example pronounce the word 'Noodles' as 'Nyudo', such that, if one is not 
very familiar with the accent, one might not be able to understand what they will be saying. The researcher has also observed that, most Chinese people speak faster than Zimbabweans such that, one may find indigenous customers constantly asking Chinese traders to repeat themselves.

The other communication strategy which is used by both Chinese Traders and indigenous customers is adjusting their message. This usually occurs when the interlocutors encounter a problem while an exchange is actually taking place. Since it would be to too late to avoid communicating, they may just abandon their message half way through or may decide to alter the meanings which they intended to communicate. They may for example, omit some items of information, make the ideas simpler or less precise or say something slightly different. This strategy does not result in any observable deviation from the conventions of correct language use.

Another strategy which is used by these two parties is approximation. Approximation usually occurs when one lacks the appropriate vocabulary or when one feels that he/she is misunderstood by his or her colleagues. A leaner may decide to use words which expresses the meaning as closely as possible. This may mean, using words which are less specific than the intended meaning for example, one may say, "Can I have some fruit", meaning a "Pineapple" it may also entail using words which really refer to something else but may be interpreted appropriately in the context of the leaner's utterance. This is a result of overgeneralization error, where one assumes that, the two words refer to one thing but no clear distinction can be made.

Both Zimbabwean customers and indigenous traders create new words or phrases which they hope will express the desired, meaning if they cannot find an appropriate word in the English language because of the language gap. Indigenous customers usually create new words by literally translating the elements in a native language. They may for example say "night table" instead of "bedside table" this is a called a transfer error

Code switching and code mixing has also proved to be the most common strategy used by the indigenous customers, who will be trying to convey their messages in English and at times run short of words. Code switching involves the use of some items of the first languages and the second language in the same discourse, which shows some knowledge gap in the second language.

The most common strategy among non-English-speaking Chinese business traders is the use propositional simplification. They simplify the way a child learns to speak their language. In effect, they expect the person they're speaking to simplify their language for better communication as well. When someone speaks fluent English, Chinese traders face some difficulties trying to understand it. They would rather speak what is termed "broken English', which is ungrammatical so that they may be understood. Some use explanations, paraphrasing and imitation, or create new words in the English language when they struggle to find the right word. We may also use stalling, prefabricated patterns or code switching to communicate and thrive in the business environment in Zimbabwe.

From the research conducted, the researcher observed that, $90 \%$ of the Chinese business traders relied on non-verbal communication strategies in order to communicate and only $10 \%$ mostly used verbal communication strategies although they include nonverbal behaviours in their communication.

\subsection{CONCLUSIONS}

It can be concluded that, most Chinese business traders and some indigenous customers rely mostly on both nonverbal and verbal communication strategies to compensate for their lack of vocabulary in the English language. They use body language especially, gestures and eye contact, to help them express themselves. They also use haptics, chronemics and paralinguistics to help them communicate with each other when conducting business together. Most Chinese traders also use electronic bilingual dictionaries to search for the meanings of words which they do not understand.

Most of the Chinese traders now rely on electronic bilingual dictionaries. Whenever they talk to their customers and encounter a word or a phrase which they do not understand, they always consult their dictionaries because they help them find the meaning of the word they are looking for, faster. This is a strategy called, asking for assistance or help, which is employed differently and helps them to survive in the business environment.

In the absence of an interpreter, Chinese traders use teleconferencing as a communication strategy. This is where by three or more people will be communicating at the same time through the use of telephones. Usually the customer will convey his or her message to the interpreter who will be somewhere, in English, the interpreter, interprets the message in Chinese to the trader who will reply in Chinese and the interpreter, gives the answer back to the customer in English.

Almost all the Chinese traders use kinesics or body language when communicating. These include the use of gestures head movement, eye contact or movement of any body part. This is the most popular strategy which is used by international which is used by international business traders.100\% of them use gestures to get their message across. This is mostly to compensate for their lack of suitable words.

From this study, it can also be concluded that, culture difference is one of the factors which impede effective intercultural communication. People from different cultures have different cultural norms. They use language differently especially on the issue of directness and politeness. Chinese people for example, use indirect speech 
when communicating, and at times they say the opposite of what they mean. In contrast, Zimbabweans use direct speech and they mean what they say. These differences might result in miscommunication and misinterpretation when the Chinese and Zimbabweans communicate. Chinese people also give importance to eye contact, as they believe that it shows that one is honest and sincere, in Zimbabwean cultures however looking at someone directly in the eyes is a sign of disrespect. This shows that, people from different cultures have different ways of interpreting non-verbal language and this usually results in, misinterpretation when people from these two cultures communicate.

The most common barriers to intercultural business communication between Chinese business traders and the indigenous customers in Zimbabwe are, language, nonverbal behaviour and differences in culture. In order to overcome these, Both Chinese traders and the indigenous customers in Zimbabwe should make an effort to learn the common language English and even the indigenous languages, for better communication. Indigenous customers together with Chinese traders should try to speak slowly, clearly, using simple language for them to understand each other and avoid misinterpretation and miscommunication.

Training programs about intercultural communication should be created in order to enhance intercultural communication competence of international business traders when they come to trade in Zimbabwe, for example, intercultural courses which are designed to teach strategies of coping with intercultural incompatibility or conflicts in business. Some organizations or institutions can also be established to design some programs consisting of lectures seminars, discussions and conflict resolution training programs or any other innovative activities regarding intercultural communication. Training programs should help learners develop comprehensive intercultural communicative ability, in order to help inter-national business traders to communicate successfully.

They should not only be taught a foreign language rules but also communication rules of a foreign culture, both verbal and non-verbal to be able to interact appropriately with people of the target country. People can avoid misunderstanding or conflict if they pay enough attention to cultural differences. They should appreciate that, cultures are different and make efforts to know the cultural norms in the target cultures but not abandoning their own customs and values

\subsection{RECOMMENDATIONS}

In light of the conclusions made from the research study, the researcher would like to recommend that:

- An investigation into the training programs about intercultural communication can be made in order to enhance intercultural communication competence of international business traders when they come to trade in Zimbabwe, for example, intercultural courses which can be designed to teach strategies of coping with intercultural incompatibility or conflicts in business. These would help students develop comprehensive intercultural communicative ability, in order to help inter-national business traders to communicate successfully. This is an area which needs further research.

- International business traders can be taught English for specific purposes (ESP) courses, for example, English for communication Purposes and English for Business Purposes so that they can function effectively in foreign countries and be able to conduct their business.

- Another area for further research could also be, investigating effective ways of making, international business traders learn language and culture and of the business environment which they will be getting in to faster, for effective communication.

\section{REFERENCES}

Bialystock, E. (1990) Communication Strategies: A Psychological Analysis of Second Ianguage use. London, Blackwell.

Brown, H. D. (2000) Principles of language learning and Teaching $4^{\text {th }}$ ed Longman. New York.

Chimhundu H, et al (1995) Report on the Formulation of a National language Policy: NationalLanguage Policy Advisory Harare.

Chiromo, A.S (2006) Research Methods and Statistics in Eduaction: A Student's guide, Gweru, Midlands State University.

Chiwomwe, E.M and Gambaya, Z. (1998) Culture and Development, Harare, Mond Books.

Cleary S. (ed) (2003): The Communication Handbook: A Student Guide to Effective Communication. Iansdown,Juta and companyLtd.

Cogo, A and Dewey, M (2006) Efficiency in ELF communication: from pragmatic motives to lexicogrammatical innovation. Nordic Journal of English Studies 5, 59-94.

Corder, S.P. (1983) "Strategies of Communication, in Faerch and Kasper (eds)

David, F (2002) Why National Pride Still has a Home in the Global Village: Global Policy Forum N.Y. The Salesman May 18

David, C (2002) English as a Global Language. Cambridge: Cambridge University Press.

Dlomo, T. (2003): Intercultural communication between Blacks and Indians in the Durba Institute of 
Technology, Unpublished M A Thesis University of Kwa-Zulu Nata-South Africa

Dornyei, Z (1997) Communication Strategies in a Second Language and Taxonomies; Language learning $47: 173-210$.

Ellis, R,(1985) Understanding Second Language Acquisition, Oxford, Oxford University Press.

Ellis, R.C (1994) The Study of Second Language Acquisition, Oxford, Oxford University Press.

Faerch, C and G. Kasper (1980) Processes and Strategies in Foreign Language Learning and Communication" Interlanguage Studies Bulletin, 4, 47-118

Gitimu, P.( 2003) Intercultural Communication: Its Importance to Various Carrier Fields and Perspectives by Various Authours. Carbondale, Southern Illinois University.

Gourdet, S. (2002) Intercultural communication between African -Ann and Zimbabwean Women: Focusing on Identity and Survival liberation, Unpublished M.A Thesis,University of South Africa, Pretoria

Hall,T (1976) Beyond Culture ;New York, Anchor

Jenkins, J (2009) English as a Lingua Franca: Attitude and Identity. Oxford: Oxford University Press.

Jandt, F.E (2001) Intercultural Communication: An Introduction ( $3^{\text {rd }}$ ed) Thousand Oaks, Sage Publications.

Kirkpatrick, A. (2013)English as an Asian lingua franca and the multilingualmodel of ELT. Cambridge: Cambridge University Press.

Kaschula, R.H and Antonissen, C (1995) Communicating Across Cultures in Southern Africa: Towards Critical Language Awareness, Johannesburg, Witwatersrand University.

Samovar, L.A and Porter R.E (1991) Communication Between Cultures, Belmont, CA: Wadsworth.

Selinker, 1 (1972) Interlanguge; International Revew of Applied Linguistics, 10;209-241.

Selinker, L. (1969) Interlanguage, IRAL, 10,209-23.

Tarrone, E. (1997) Conscious Communication Strategies in Interlanguage: A ProgressReport", in Brown, H.D, YarioC.A ,Crimes, R.H (ed) on Tesol 77, Washington DC. 